\title{
Syntheses of Poly(ethylene oxide-b-styrene oxide) Macromonomers and Their Application to Emulsion and Dispersion Copolymerizations with Styrene
}

\author{
Hirokazu IMAI,${ }^{\dagger \dagger}$ Seigou KaWAGUCHI, ${ }^{*}$ and Koichi ITO ${ }^{\dagger}$ \\ Department of Materials Science, Toyohashi University of Technology, \\ Tempaku-cho, Toyohashi 441-8580, Japan \\ *Department of Polymer Science and Engineering, Faculty of Engineering, Yamagata University, \\ Jonan, Yonezawa 992-8510, Japan
}

(Received February 18, 2003; Accepted April 2, 2003)

\begin{abstract}
Poly(ethylene oxide- $b$-styrene oxide) macromonomers carrying $p$-vinylbenzyl ether end group were prepared by sequential anionic polymerization of ethylene oxide and styrene oxide with potassium 2-methoxyethoxide, followed by reaction with $p$-vinylbenzyl bromide to the end-group functionality up to $85 \%$. The macromonomers have been successfully applied to emulsion and dispersion copolymerizations with styrene to afford monodisperse polymeric microsheres in water and in methanol-water $(9 / 1 \mathrm{v} / \mathrm{v})$ mixture, respectively. Incorporation of the macromonomer into the particle is more effective, so resulting in smaller particle size, in the emulsion than in the dispersion system. The particle size in the latter system decreased with the macromonomer concentration in accord with a previously proposed power-law theory and with the chain length of the styrene oxide block.

KEY WORDS Macromonomers / Ethylene Oxide / Styrene Oxide / Block / p-Vinylbenzyl EndGroup / Emulsion / Dispersion /
\end{abstract}

Amphiphilic macromonomers find increasing concern in view of their potential use for preparation of polymeric microspheres of submicron to micron size by emulsion and dispersion copolymerizations with a hydrophobic monomer in water and alcoholic media, respectively, without conventional surfactants ('soapfree'). They are usually composed of hydrophilic polymer chains (tails) and the hydrophobic polymerizable end groups (heads), which copolymerize in situ with a substrate hydrophobic monomer to afford graft copolymers. So they serve as effective stabilizers firmly (covalently) attached on the particle surfaces in such a manner that the hydrophobic heads act as anchors while the hydrophilic tails work as steric stabilizers against flocculation. So far a lot of macromonomers have been reported for design of various kinds of polymer microspheres. ${ }^{1-5}$

In design of such macromonomers, considerable attention has been paid for control of hydrophiliclyophilic balance (HLB). To our experience, properly hydrophobically enhanced heads as well as properly long hydrophilic tails appear to be important in fine size control and stability of the microspheres to be obtained. In case of poly(ethylene oxide) (PEO) macromonomers with styryl or methacrylate end groups, introduction of some alkylene spacers ${ }^{6-9}$ has been successful in this regard. Also interesting is the amphiphilic macromonomer of block copolymer type, ${ }^{10-14}$ in which hydrophilic segments are connected through hydrophobic segments to polymerizable end groups. Examples include block macromonomers from poly(2oxazoline)s, ${ }^{10,11}$ PEO-b-polystyrene (PSt), ${ }^{12}$ PEO- $b$ poly(butylene oxide), ${ }^{13}$ and PEO- $b$-polylactide. ${ }^{14}$

In extension of our PEO macromonomer studies, in this paper we discuss preparation of PEO- $b$ poly(styrene oxide) (PSO) macromonomers with $p$ vinylbenzyl (VB) end groups for use in emulsion and dispersion copolymerization with styrene. Here we expected that PSO segments with VB would provide good balance with the hydrophilic PEO chains for particle size control. The surface properties of PEO- $b$ PSO block copolymers as recently reported by Mai et $a l .{ }^{15}$ stimulated the present work on their transformation into the corresponding macromonomers. The process is given in Scheme 1.

\section{EXPERIMENTAL}

\section{Materials}

$p$-Vinylbenzyl bromide (VBB) was prepared from $p$-vinylbenzyl chloride (VBC) by reaction with sodium bromide in the presence of tetrabutylammonium bromide as described before. ${ }^{16}$ Styrene, 2,2'-azobisisobutyronitrile (AIBN), and potassium

\footnotetext{
${ }^{\dagger}$ To whom correspondence should be addressed (Tel: +81-532-44-6814, Fax +81-532-48-5833, E-mail: itoh@tutms.tut.ac.jp).

${ }^{\dagger}$ Present address: AICA Kogyo Co., Ltd., R\&D Center, 24 Fukami, Jimokuji-cho, Ama-gun, Aichi 490-1112, Japan.
} 


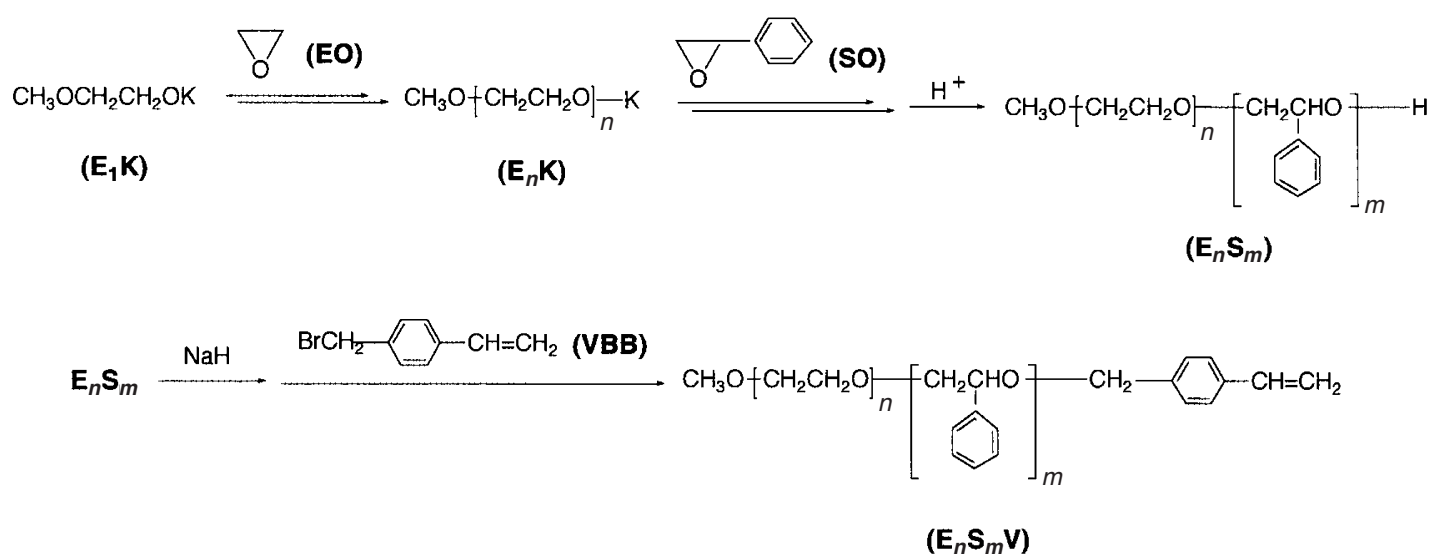

Scheme 1.

persulfate (KPS) were purified by usual procedures as described. ${ }^{7,17}$ Potassium 2-methoxyethoxide $\left(\mathrm{CH}_{3} \mathrm{OCH}_{2} \mathrm{CH}_{2} \mathrm{OK}\right)$ was prepared under vacuum by reaction of potassium mirror with excess 2methoxyethanol, followed by evaporation of the alcohol to dryness, and finely dispersed in tetrahydrofuran (THF) by magnetic stirring. Styrene oxide (SO) from Wako Pure Chemical Co. was distilled over calcium hydride $\left(\mathrm{CaH}_{2}\right)$ under a reduced pressure, stirred over $\mathrm{CaH}_{2}$ under a vacuum line over night, and distilled into calibrated ampoules with a breakable seal. Sodium hydride $(60 \% \mathrm{NaH}$ in oil) was used as supplied (Kishida Chemical). EO and THF were purified under vacuum as before. ${ }^{18,19}$

\section{Polymerization of EO and SO}

Polymerization was conducted under high vacuum with a conventional breakable seal technique. ${ }^{18,19}$ First, EO (14 mL, $287 \mathrm{mmol})$ was polymerized in THF $(130 \mathrm{~mL}$ in total) with potassium 2-methoxyethoxide $(6.9 \mathrm{mmol})$ at $40^{\circ} \mathrm{C}$. The dispersion of the initiator became transparent in a few hours after heating, indicating the progress of polymerization. After polymerization for $24 \mathrm{~h}$, an aliquot was poured into hexane. The precipitate was dried and characterized by size exclusion chromatography (SEC) (Figure 1a) and nuclear magnetic resonance $\left({ }^{1} \mathrm{H}\right.$ NMR) (Figure $\left.2 \mathrm{a}\right)$. The yield was quantitative. The number-average degree of polymerization, $n$, by SEC was 41 , in good accord with the value 42.6 expected for the living polymerization with $100 \%$ initiator efficiency and $100 \%$ conversion $(n=1+287 / 6.9)$. The molecular weight distribution was also sharp with $M_{\mathrm{w}} / M_{\mathrm{n}}=1.12$.

The remaining solution in the polymerization flask was divided under vacuum into three parts for block copolymerization of $\mathrm{SO}$. Each part was evacuated to the dry solid, $\mathrm{CH}_{3} \mathrm{O}\left[\mathrm{CH}_{2} \mathrm{CH}_{2} \mathrm{O}\right]_{n} \mathrm{~K}$ (denoted as $\mathrm{E}_{n} \mathrm{~K}$ ), into which $\mathrm{SO}$ was introduced when the color changed to brown to dark red. Polymerization of
SO in bulk was continued at $65^{\circ} \mathrm{C}$ for a week and at $80^{\circ} \mathrm{C}$ for further one week. Methanol was introduced to quench the reaction and the mixture was poured into diethyl ether. After three times reprecipitation from THF into diethyl ether, the yellowcolored polymers were freeze-dried from benzene to give $\mathrm{CH}_{3} \mathrm{O}\left[\mathrm{CH}_{2} \mathrm{CH}_{2} \mathrm{O}\right]_{n}\left[\mathrm{CH}_{2} \mathrm{CH}(\mathrm{Ph}) \mathrm{O}\right]_{m} \mathrm{H}$, denoted as $\mathrm{E}_{n} \mathrm{~S}_{m}$. Conversion of $\mathrm{SO}$ was low up to about 33 to $40 \%$, as estimated by ${ }^{1} \mathrm{H}$ NMR (Figure $2 b$ ). So the degree of polymerization of $\mathrm{SO}, m$, was controlled by the amount of SO charged. Thus, $m \approx(0.33-$ $0.40) \times[\mathrm{SO}]_{\mathrm{o}} /[\mathrm{K}]_{\mathrm{o}}$ for the above condition, where $[\mathrm{SO}]_{\mathrm{o}} /[\mathrm{K}]_{\mathrm{o}}$ is the mole ratio of $\mathrm{SO}$ to $\mathrm{E}_{n} \mathrm{~K}$ in feed.

\section{End-Group Transformation}

Into a three-necked flask under $\mathrm{Ar}$ atmosphere, sodium hydride in oil was introduced, washed with hexane, and dried under vacuum. The block copolymer, $\mathrm{E}_{n} \mathrm{~S}_{m}$, dissolved in dry THF was introduced and the mixture was stirred for alkoxidation at room temperature for $2 \mathrm{~h}$. VBB was added and the mixture was stirred at $30^{\circ} \mathrm{C}$ over night in dark. The content was diluted by benzene and the precipitated salts were filtered. The filtrate was poured into diethyl ether, three times reprecipitated, and freeze-dried from benzene. The polymers were obtained as almost whiteor light yellow-colored powders. A typical recipe of the reaction was $\mathrm{E}_{n} \mathrm{~S}_{m} 1.6 \mathrm{mmol} / \mathrm{NaH} 32 \mathrm{mmol} / \mathrm{VBB}$ $16 \mathrm{mmol} / \mathrm{THF} 50 \mathrm{~mL}$. End-group functionality of the final macromonomers, denoted as $\mathrm{E}_{n} \mathrm{~S}_{m} \mathrm{~V}$, was found to be $75-85 \%$ as estimated by the intensity ratio of the peaks due to vinyl and oxyethylene protons in ${ }^{1} \mathrm{H}$ NMR (Figure 2c).

\section{Emulsion and Dispersion Copolymerizations}

Stable emulsion of styrene in water with the block macromonomer, $\mathrm{E}_{n} \mathrm{~S}_{m} \mathrm{~V}$, was easily obtained by mechanical or magnetic stirring. Copolymerization was carried out in a flask with a mechanical stirrer at $65^{\circ} \mathrm{C}$ 
for one day with KPS as an initiator as described before. ${ }^{7}$ Dispersion copolymerization was conducted at $60^{\circ} \mathrm{C}$ in methanol-water mixture $(9 / 1 \mathrm{v} / \mathrm{v})$ with AIBN as an initiator. Styrene, macromonomer, and methanolwater mixture with AIBN were charged into a roundbottomed glass tube with a magnetic stirrer tip. The tube was degassed three times by freeze-thaw in vacuum, sealed off, and placed in a heated bath to start the polymerization. The clear solution became immediately cloudy to a latex and the mixture was stirred magnetically for one day. The average size and distribution of the particles obtained were analyzed for one hundred particles in the scanning electron microscopy (SEM) or transmission electron microscopy (TEM) photographs taken after dilution with methanol. Conversion of styrene was almost quantitative as determined by gravimetry. ${ }^{7,} 17$ The particles were purified by centrifugal separation with methanol to remove the unreacted macromonomers, as confirmed by SEC. Their composition was estimated by ${ }^{1} \mathrm{H}$ NMR from the peak intensity ratio of the phenyl to oxyethylene protons.

\section{Characterization}

Measurements of ${ }^{1} \mathrm{H}$ NMR in $\mathrm{CDCl}_{3}$ (Mercury Varian 300), SEC with THF as an eluent $\left(1 \mathrm{~mL} \mathrm{~min}^{-1}\right)$ (JASCO PU980 pump) with RI (RI980) and UV (Uvidec-10-III) detectors, and SEM (Hitachi S-2300) were carried out as described before. ${ }^{17,19}$ TEM was measured on Hitachi H-800 Microscope working at $200 \mathrm{kV}$ accelerating voltage with a sample prepared from $0.2 \mathrm{wt} \%$ aqueous emulsion coated on a 200 mesh collodion sheet (Nissin EM Co.).

\section{RESULTS AND DISCUSSION}

\section{Preparation of EO-SO Block Macromonomers}

Polymerization of EO with potassium 2methoxyethoxide $\left(\mathrm{E}_{1} \mathrm{~K}\right)$ proceeded in a living fashion to afford methoxy-ended PEO K-alkoxide $\left(\mathrm{E}_{n} \mathrm{~K}\right)$ as previously reported. ${ }^{20}$ Thus the degree of polymerization as determined by SEC (Figure 1a) was very close to that predicted by the molar ratio of $\mathrm{EO}$ to the initiator charged, i.e., $n=1+[\mathrm{EO}]_{\mathrm{o}} /\left[\mathrm{E}_{1} \mathrm{~K}\right]_{\mathrm{o}}$, and the molecular weight distribution was narrow with $M_{\mathrm{w}} / M_{\mathrm{n}}=1.12$. In ${ }^{1} \mathrm{H}$ NMR spectrum (Figure $2 \mathrm{a}$ ), the intensity ratio of the methoxy (a) and oxyethylene (b) peaks at $\delta 3.4$ and $\delta 3.7$, respectively, was also very close to that expected, i.e., $3 / 4 n$, supporting the incorporation of the methoxy end-group as an initiator fragment in each polymer chain.

Subsequent polymerization of $\mathrm{SO}$ with $\mathrm{E}_{n} \mathrm{~K}$ to $\mathrm{E}_{n} \mathrm{~S}_{m} \mathrm{~K}$, however, was extremely slow as reported by Mai et al. ${ }^{15}$ Indeed, the conversion was up to $40 \%$ after

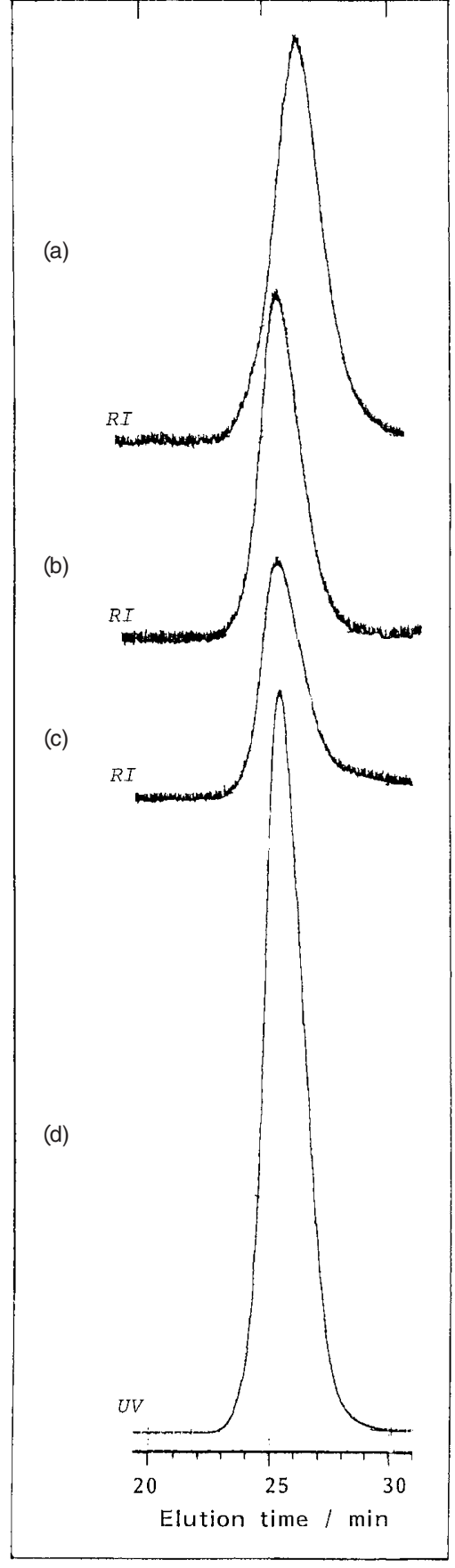

Figure 1. $\mathrm{SEC}$ traces of (a) $\mathrm{E}_{41}$, (b) $\mathrm{E}_{41} \mathrm{~S}_{4.1}$, (c) $\mathrm{E}_{41} \mathrm{~S}_{4.1} \mathrm{~V}$ with $\mathrm{RI}$ detector, and (d) $\mathrm{E}_{41} \mathrm{~S}_{4.1} \mathrm{~V}$ with $\mathrm{UV}$ detector.

polymerization at $65^{\circ} \mathrm{C}$ for a week and at $80^{\circ} \mathrm{C}$ for further one week. The degree of polymerization, $m$, was controlled by the ratio of SO/ $\mathrm{E}_{n} \mathrm{~K}$. The SEC peak after SO polymerization (Figure 1b) was found just to shift parallel to higher molecular weight side and the corresponding peak by UV detector showed a very similar response, just like Figure 1d for $\mathrm{E}_{n} \mathrm{~S}_{m} \mathrm{~V}$, indicating that the block copolymerization proceeded smoothly and evenly on each $\mathrm{E}_{n} \mathrm{~K}$ chain.

Direct reaction of $\mathrm{E}_{n} \mathrm{~S}_{m} \mathrm{~K}$ with VBB in THF, including unreacted $\mathrm{SO}$, was first attempted in a vacuum system but not successful, so the alcohol, $\mathrm{E}_{n} \mathrm{~S}_{m}$, 
(a)

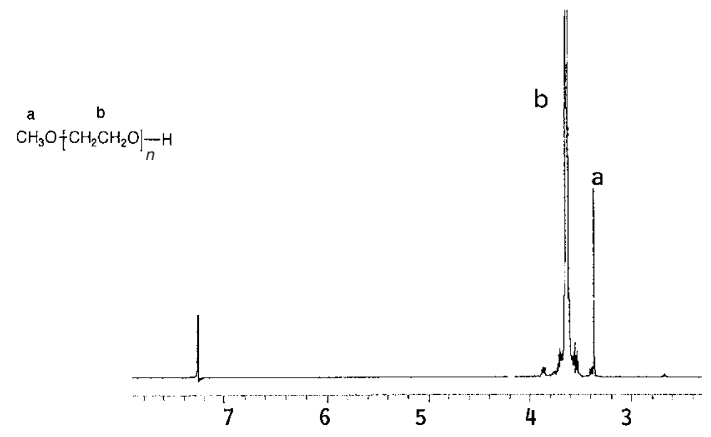

(b)

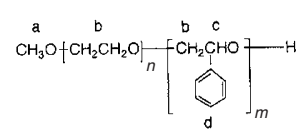

(c)

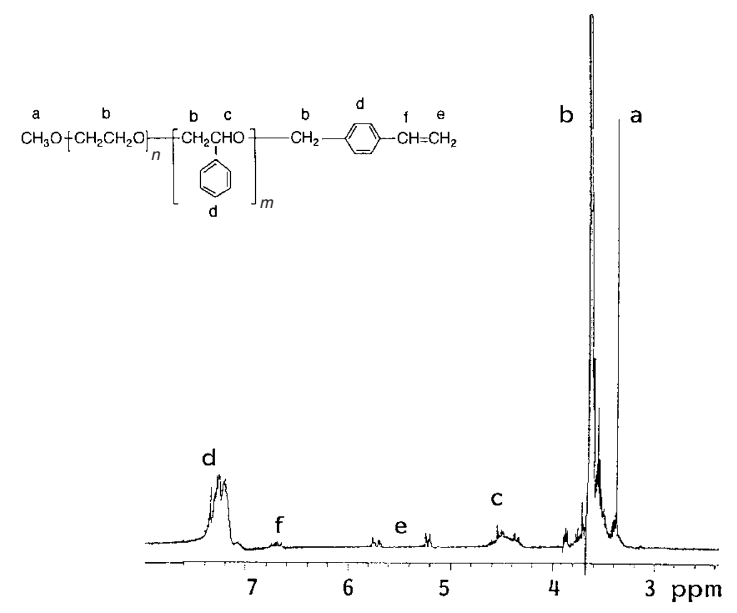

Figure 2. ${ }^{1} \mathrm{H}$ NMR spectra of (a) $\mathrm{E}_{41}$, (b) $\mathrm{E}_{41} \mathrm{~S}_{4.1}$, and (c) $\mathrm{E}_{41} \mathrm{~S}_{4.1} \mathrm{~V}$.

was isolated and reacted with very large excess of $\mathrm{NaH}$ and VBB in THF (Williamson synthesis) at $30^{\circ} \mathrm{C}$ over night. The incorporation of $p$-vinyl benzyl end group was not quite high but $75-85 \%$ as estimated by ${ }^{1}$ H NMR (Figure 2c). Results of characterization of the final block macromonomers obtained, $\mathrm{E}_{n} \mathrm{~S}_{m} \mathrm{~V}$, are summarized in Table I.

The very slow reaction found for $\mathrm{E}_{n} \mathrm{~S}_{m} \mathrm{~K}$ with $\mathrm{SO}$ (propagation) as well as VBB (termination) appears to be due to steric repulsion among the bulky phenyl rings of the reactants. This slowness as well as severe reaction condition (high temperature) made no use of the initiation method using $p$-vinylbenzyl alcohol Kalkoxide as an initiator for block copolymerization of
Table I. Characterization of block macromonomers, $\mathrm{E}_{n} \mathrm{~S}_{m} \mathrm{~V}$

\begin{tabular}{llcc}
\hline Code $^{\mathrm{a}}$ & $M_{\mathrm{n}}{ }^{\mathrm{b}}$ & $M_{\mathrm{w}} / M_{\mathrm{n}}{ }^{\mathrm{b}}$ & $f^{\mathrm{c}}$ \\
\hline $\mathrm{E}_{41} \mathrm{~S}_{2.6} \mathrm{~V}$ & 2400 & 1.12 & 0.85 \\
$\mathrm{E}_{41} \mathrm{~S}_{4.1} \mathrm{~V}$ & 2500 & 1.15 & 0.82 \\
$\mathrm{E}_{41} \mathrm{~S}_{6.8} \mathrm{~V}$ & 3000 & 1.25 & 0.75 \\
\hline
\end{tabular}

${ }^{\mathrm{a}}$ The subscript numbers after $\mathrm{E}$ and $\mathrm{S}$ denote numberaverage degree of polymerization of $\mathrm{EO}$ and $\mathrm{SO}$, as determined by SEC and ${ }^{1} \mathrm{H}$ NMR, respectively. ${ }^{b}$ Determined by SEC calibrated with poly(ethylene glycol)s. ${ }^{\mathrm{c} E n d-g r o u p ~(~} p$-vinylbenzyl) functionality as determined by ${ }^{1} \mathrm{H}$ NMR.

SO and EO, in contrast to the successful case of butylene oxide and EO reported by Guyot et al. ${ }^{13}$

\section{Application to Emulsion and Dispersion Copolymer- ization with Styrene}

The block macromonomers obtained, $\mathrm{E}_{n} \mathrm{~S}_{m} \mathrm{~V}$, were successfully applied to emulsion and dispersion copolymerizations with styrene to obtain monodisperse polystyrene microspheres of submicron to micron size. Typical TEM and SEM photographs are shown in Figure 3, with the characterization data in Table II.

As a most probable model of the microsphere, we assume core-shell structure in which the core consists of polystyrene chains and the shell of PEO chains. ${ }^{6}$ Then, we have:

$$
\begin{aligned}
R & =\left(3 M_{\mathrm{D}} W_{\mathrm{So}} \theta_{\mathrm{S}}\right) /\left(\rho W_{\mathrm{Do}} \theta_{\mathrm{D}} N_{\mathrm{A}} S\right) \\
& =\left(3 m_{\mathrm{S}} M_{\mathrm{S}}\right) /\left(\rho N_{\mathrm{A}} m_{\mathrm{D}} S\right)
\end{aligned}
$$

where $R$ is the particle radius, $W_{\text {So }}$ the weight of the substrate monomer (styrene) in feed, $\theta_{\mathrm{S}}$ its conversion of polymerization, $\rho$ the density of its polymer, $W_{\text {Do }}$ the weight of the macromonomer in feed, $\theta_{\mathrm{D}}$ its conversion copolymerized or grafted on the surface, $M_{\mathrm{D}}$ the molecular weight of the macromonomer, $S$ the crosssectional area occupied by each grafted macromonomer chain on the particle surface, and $N_{\mathrm{A}}$ the Avogadro's number. With $m_{\mathrm{S}}$ and $m_{\mathrm{D}}$ denoting for the moles of the substrate monomer and the macromonomer incorporated into the particle core and surface, respectively, and $M_{\mathrm{S}}$ for the molecular weight of the substrate monomer, we have $\left(W_{\mathrm{So}} \theta_{\mathrm{S}}\right) /\left(W_{\mathrm{Do}} \theta_{\mathrm{D}}\right)=\left(m_{\mathrm{S}} M_{\mathrm{S}}\right) /$ $\left(m_{\mathrm{D}} M_{\mathrm{D}}\right)$ and then the last equation in eq 1.

In the present case with styrene and $\mathrm{E}_{41} \mathrm{~S}_{4.1} \mathrm{~V}$, $M_{\mathrm{S}}=104, M_{\mathrm{D}}=2500$, and by assuming $\rho=1 \mathrm{~g} \mathrm{~cm}^{-3}$, we have the relationships: $R=0.52 m_{\mathrm{S}} /\left(m_{\mathrm{D}} S\right)$ with $R$ and $S$ in units of $\mathrm{nm}$ and $\mathrm{nm}^{2}$, respectively, and $\theta_{\mathrm{S}} / \theta_{\mathrm{D}}=\left(m_{\mathrm{S}} / m_{\mathrm{D}}\right) / 24\left(W_{\mathrm{So}} / W_{\text {Do }}\right)$. Table II includes the related parameters calculated from $R=D_{\mathrm{n}} / 2$ and $m_{\mathrm{S}} / m_{\mathrm{D}}$ observed. Here it is to be noted that we used the value of $W_{\text {Do }}$ after corrected for the incomplete functionality of the vinyl end group: i.e., $W_{\text {Do }}=f \times$ the weight of the macromonomer charged in feed, where 


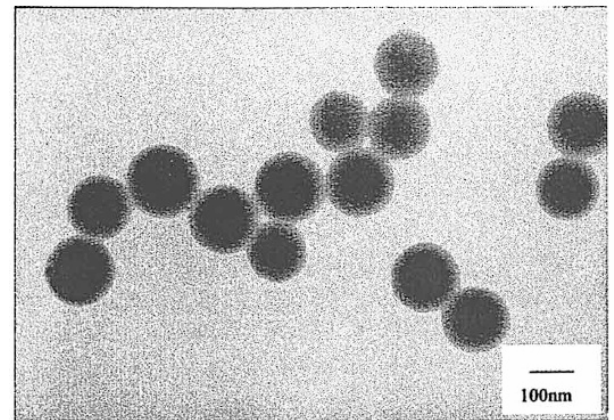

(a)

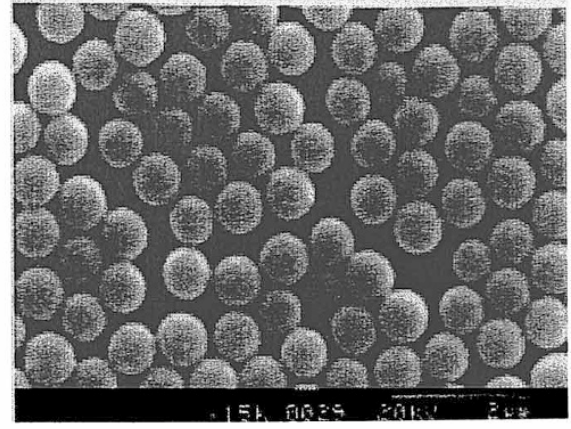

(b)

Figure 3. (a) TEM and (b) SEM photographs of the particles obtained by emulsion and dispersion copolymerizations, respectively. See Table I for characterization data.

Table II. Emulsion and Dispersion Copolymerizations of Styrene with $\mathrm{E}_{41} \mathrm{~S}_{4.1} \mathrm{~V}$

\begin{tabular}{lcccccccc}
\hline & $W_{\mathrm{So}} / W_{\text {Do }}$ & $\frac{D_{\mathrm{n}}{ }^{\mathrm{c}}}{(\mathrm{nm})}$ & $\frac{D_{\mathrm{w}} / D_{\mathrm{n}} \mathrm{c}^{\mathrm{c}}}{}$ & $\frac{m_{\mathrm{S}} / m_{\mathrm{D}}{ }^{\mathrm{d}}}{(\mathrm{g})}$ & $\frac{S^{\mathrm{e}}}{(\mathrm{mol} / \mathrm{mol})}$ & $\frac{\left\langle R_{\mathrm{g}}\right\rangle^{\mathrm{f}}}{\left(\mathrm{nm}^{2}\right)}$ & $\frac{2}{(\mathrm{~nm})}$ & $\theta_{\mathrm{S}} / \theta_{\mathrm{D}}{ }^{\mathrm{g}}$ \\
\hline Emulsion $^{\mathrm{a}}$ & 15.2 & 168 & 1.01 & 400 & 2.5 & 0.89 & 1.1 \\
Dispersion $^{\mathrm{b}}$ & 15.2 & 726 & 1.01 & 1100 & 1.6 & 0.71 & 3.0 \\
\hline
\end{tabular}

${ }^{\mathrm{a}}$ Feed: styrene $\left(W_{\mathrm{So}}\right)=8 \mathrm{~g}, E_{41} S_{4.1} \mathrm{~V}\left(W_{\text {Do }}\right)=0.64 \mathrm{~g} \times 0.82, \mathrm{KPS}=80 \mathrm{mg}$, water $=80 \mathrm{~mL}$. Temperature: $65^{\circ} \mathrm{C}$. Polymerization time: $24 \mathrm{~h}$. Styrene conversion: nearly quantitative $\left(\theta_{\mathrm{S}}=1\right)$. ${ }^{\mathrm{b}}$ Feed: styrene $\left(W_{\mathrm{So}}\right)=1 \mathrm{~g}, E_{41} S_{4.1} \mathrm{~V}$ $\left(W_{\text {Do }}\right)=0.08 \mathrm{~g} \times 0.82$, AIBN $=20 \mathrm{mg}$, methanol-water $(9 / 1 \mathrm{v} / \mathrm{v})=10 \mathrm{~mL}$. Temperature: $60^{\circ} \mathrm{C}$. Polymerization time: $24 \mathrm{~h}$. Styrene conversion: nearly quantitative $\left(\theta_{\mathrm{S}}=1\right) .{ }^{\mathrm{c}} D_{\mathrm{n}}$ and $D_{\mathrm{w}}$ : number- and weight-average particle diameters from TEM or SEM. ${ }^{\mathrm{d} S t y r e n e / m a c r o m o n o m e r ~ m o l e ~ r a t i o ~ i n ~ p a r t i c l e ~ f r o m ~}{ }^{1} \mathrm{H}$ NMR. ${ }^{\mathrm{e}}$ Crosssectional area per macromonomer chain on particle surface from $R=D_{\mathrm{n}} / 2$ and $m_{\mathrm{S}} / m_{\mathrm{D}}$ with eq 1 , with $M_{\mathrm{S}}=104$ and assuming $\rho=1 \mathrm{~g} \mathrm{~cm}^{-3}$. ${ }^{\mathrm{f}}$ Average radius of gyration of each macromonomer chain occupying the cross-sectional area on particle surface: $\left\langle R_{\mathrm{g}}\right\rangle=(S / \pi)^{1 / 2}$. ' Ratio of conversion of styrene to macromonomer: $\theta_{\mathrm{S}} / \theta_{\mathrm{D}}=\left(m_{\mathrm{S}} M_{\mathrm{S}} / m_{\mathrm{D}} M_{\mathrm{D}}\right)\left(W_{\mathrm{Do}} / W_{\mathrm{So}}\right)$.

$f$ is the functionality as given in Table I. Starting with the same recipe, the emulsion system clearly produced much smaller microspheres than the dispersion system, as usually observed. This can be attributed to much lower incorporation of the macromonomer into the particles in the latter. Thus the lower $\theta_{\mathrm{D}} / \theta_{\mathrm{S}}$ or $m_{\mathrm{D}} / m_{\mathrm{S}}$ results in smaller coverage of the macromonomer (PEO) chains on the particle surfaces leading to a larger size in the dispersion system. On the other hand, the conformation of each PEO chain tethered on the surface, as judged by $S$ or $\left\langle R_{\mathrm{g}}\right\rangle$, appears essentially the same in either system. The values, however, are much smaller than those expected for free, random PEO chains with $n=41, S_{\text {random }}=13 \mathrm{~nm}^{2}$ and, $\left\langle R_{\mathrm{g}}\right\rangle_{\text {random }}=1.6 \mathrm{~nm}$, calculated from $S_{\text {random }}=(5 / 3) \pi\left\langle R_{\mathrm{g}}\right\rangle^{2}$ with $\left\langle R_{\mathrm{g}}{ }^{2}\right\rangle^{1 / 2}=0.02$ $M_{\mathrm{W}}{ }^{0.58}$ for PEO at $25^{\circ} \mathrm{C}$ in water or methanol. ${ }^{6 a, 21}$ The last comparison supports the idea that the PEO chains copolymerized in the final particles extend cylindrically right on the particle surfaces rather than randomly expand over the surface, as already pointed out. 6,22

The reason why macromonomers appear much less reactive in the dispersion system is not very clear at present, but we suppose as follows. Excessive mo- lar amounts of styrene and the macromonomers dissolved molecularly in methanol-water $(9 / 1 \mathrm{v} / \mathrm{v})$ mixture will polymerize and/or copolymerize to give insoluble polystyrenes and styrene-rich copolymers, which will coalesce together to originate the sterically stabilized microparticles, which will in turn grow in size by polymerization and copolymerization of the monomers. Here styrene monomers appear to be more easily occluded in the particles because the incorporation of the macromonomers will be hindered sterically by the already grafted PEO chains covering the surface. As a consequence, the final particles characterized by lower $m_{\mathrm{D}}$ or $\theta_{\mathrm{D}}$ (higher $m_{\mathrm{S}} / m_{\mathrm{D}}$ or $\theta_{\mathrm{S}} / \theta_{\mathrm{D}}$ ) will result with larger size as compared to the emulsion system. On the other hand, essentially all styrene monomers and the macromonomers are included in the emulsion droplets ab initio and are supposed to polymerize and/or copolymerize in roughly azeotropic manner. ${ }^{7,23}$ Here we are reminded of a mechanism of miniemulsion polymerization, ${ }^{24,25}$ since the styrene emulsions are easily made by addition of the amphiphilic PEO macromonomers and appear to polymerize as such, and interestingly in the present case, without any additives such as higher 


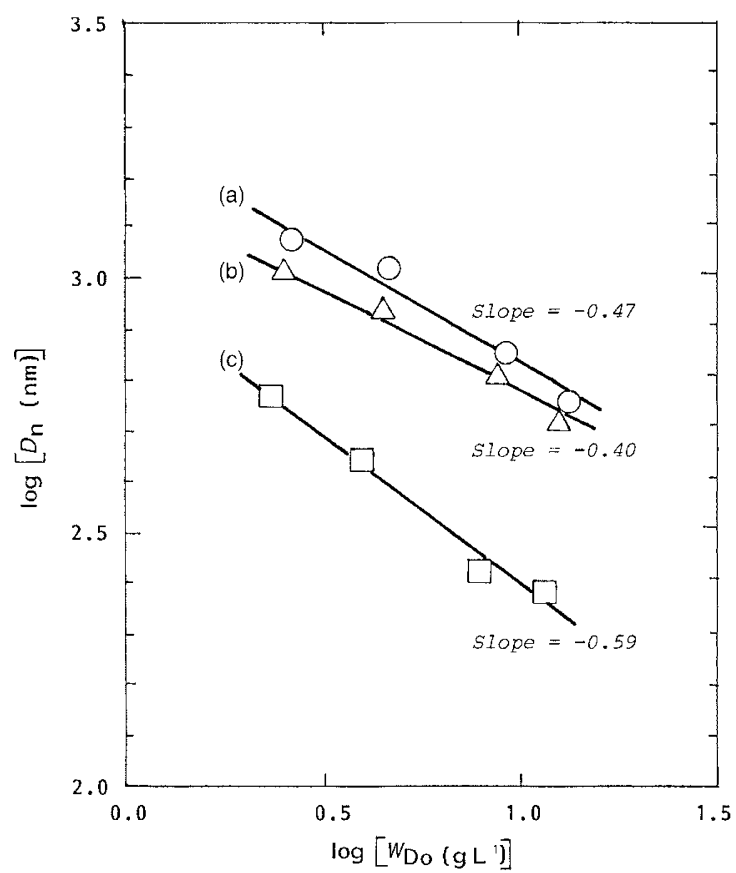

Figure 4. Double logarithm plots of particle diameter $\left(D_{\mathrm{n}}\right)$ vs macromonomer concentration $\left(W_{\mathrm{Do}}\right)$ in dispersion copolymerization: (a) $E_{41} S_{2.6} V$, (b) $E_{41} S_{4.1} V$, and (c) $E_{41} S_{6.8} V$. Slopes are for the least-squared straight lines.

alkanes or alcohols. Further study is needed to confirm the clear mechanism and for further application.

Eq 1 does not mean that the particle size is a direct function of $W_{\mathrm{So}} / W_{\text {Do }}$ since $\theta_{\mathrm{S}}, \theta_{\mathrm{D}}$ as well as $S$ are interrelated variable quantities. Based on the kinetic simulation together with the homogeneous nucleation mechanism by Paine, ${ }^{26}$ we proposed an eq for the particle size in dispersion copolymerization: ${ }^{6}$

$$
\begin{aligned}
R= & \theta_{\mathrm{S}}{ }^{1 / 3}\left(3 W_{\mathrm{So}} / \rho N_{\mathrm{A}}\right)^{2 / 3}\left(M_{\mathrm{D}} r_{1} / W_{\mathrm{Do}} S_{\text {crit }}\right)^{1 / 2} \\
& \times\left(0.386 k_{2} / 4 \pi k_{\mathrm{p}}\right)^{1 / 6}\left(k_{\mathrm{t}} / 2 k_{\mathrm{d}} f[\mathrm{I}]_{\mathrm{o}}\right)^{1 / 12}
\end{aligned}
$$

where $S_{\text {crit }}$ is $S$ at critical point where the sterically stabilized particle formation is established, $r_{1}$ is the substrate monomer reactivity ratio in copolymerization with the macromonomer before the critical point, $k_{2}$ is the diffusion-controlled rate constant for coalescence of similar-sized microparticles, $k_{\mathrm{p}}$ and $k_{\mathrm{t}}$ are the propagation and termination rate constants of polymerization of the substrate monomer, and $k_{\mathrm{d}}, f$, and $[\mathrm{I}]_{\mathrm{o}}$ are the decomposition rate constant, initiator efficiency, and the initiator concentration, respectively. After the critical point, the sterically stabilized particles are assumed to coalesce no more, with the number of such particles remaining constant. Thus the particle size should depend on $W_{\mathrm{So}}{ }^{2 / 3} W_{\mathrm{Do}}{ }^{-1 / 2}$, as observed in dispersion copolymerization of styrene or $n$-butyl methacrylate with PEO macromonomers. ${ }^{6}$

The effects of the type and the concentration of the present block macromonomers on the particle size are given in the $\log -\log$ plots of $D_{\mathrm{n}} v s . W_{\text {Do }}$ in Figure 4 for the final particles obtained $\left(\theta_{\mathrm{S}} \approx 1\right)$, again using $W_{\mathrm{Do}^{-}}$ values corrected for imperfect functionality. The slopes are close to the theoretical value of $-1 / 2$, supporting the proposed nucleation and growth mechanism. The particle size decreased significantly with increasing chain length of SO segments, $m$, of the block macromonomer. It appears that the increased hydrophobicity of the polymerizing end group enhances its copolymerizability with styrene (lower $r_{1}$ ) in methanol-water mixture.

In conclusion, block macromonomers, $\mathrm{E}_{n} \mathrm{~S}_{m} \mathrm{~V}$, were prepared by successive anionic polymerization of $\mathrm{EO}$ and SO, followed by Williamson synthesis with VBB. End-group functionality was $75-85 \%$. The effect of the hydrophobic SO block inserted between the polymerizing end group and the PEO chain was striking to control the emulsion and dispersion copolymerizations with styrene to monodisperse microspheres, since the PEO macromonomers without SO blocks are not so effective but give rise to particles with broader distribution or even some coagulations. The effect of the imperfect end-group functionalization, however, remains to be studied, together with the effort to achieve more perfect functionalization.

\section{REFERENCES}

1. K. Ito and S. Kawaguchi, Adv. Polym. Sci., 142, 129 (1999).

2. A. Guyot and K. Tauer, Adv. Polym. Sci., 111, 43 (1994).

3. J. M. Asua and H. A. Schoonbrood, Acta Polym., 49, 671 (1998).

4. A. Guyot, in "Functional Polymer Colloids \& Microparticles", R. Arshady and A. Guyot, Eds., Citus Books, London, 2002, p 77.

5. K. Ito, J. Cao, and S. Kawaguchi, in "Functional Polymer Colloids \& Microparticles", R. Arshady and A. Guyot, Eds., Citus Books, London, 2002, p 109.

6. a) S. Kawaguchi, M. A. Winnik, and K. Ito, Macromolecules, 28, 1159 (1995).

b) M. B. Nugroho, S. Kawaguchi, K. Ito, and M. A. Winnik, Macromol. Rep., A32, 593 (1995).

7. S. Kawaguchi, K. Tano, M. Maniruzzaman, and K. Ito, Macromol. Symp., 150, 101 (2000).

8. H. Furuhashi, S. Kawaguchi, S. Itsuno, and K. Ito, Colloid Polym. Sci., 275, 227 (1997).

9. a) J. Liu, C. H. Chew, and L. M. Gan, J. Macromol. Sci.-Pure Appl. Chem., A33, 337 (1996).

b) J. Liu, C. H. Chew, S. Y. Wong, and L. M. Gan, J. Macromol. Sci.-Pure Appl. Chem., A33, 1181 (1996).

10. H. Uyama, Y. Matsumoto, and S. Kobayashi, Chem. Lett., 2401 (1992).

11. H. Uyama, Y. Honda, and S. Kobayashi, J. Polym. Sci., Part A: Polym. Chem., 31, 123 (1993).

12. S. Gibanel, V. Heroguez, J. Forcada, and Y. Gnanou, Macromolecules, 35, 2467 (2002).

13. a) O. Soula and A. Guyot, Langmuir, 15, 7956 (1999).

b) O. Soula, R. Petiaud, M.-F. Liauro, and A. Guyot, Macro- 
molecules, 32, 6938 (1999).

14. M. Iizima, Y. Nagasaki, T. Okada, M. Kato, and K. Kataoka, Macromolecules, 32, 1140 (1999).

15. S. Mai, C. Booth, A. Kelarakis, V. Havredaki, and A. J. Ryan, Langmuir, 16, 1681 (2000).

16. H. Yoshida, S. Itsuno, and K. Ito, Can. J. Chem., 73, 1757 (1995).

17. M. Maniruzzaman, S. Kawaguchi, and K. Ito, Macromolecules, 33, 1583 (2000).

18. K. Ito, H. Tsuchida, A. Hayashi, T. Kitano, E. Yamada, and T. Matsumoto, Polym. J., 17, 827 (1985).

19. T. Senyo, Y. Atago, H. Liang, R. Shen, and K. Ito, Polym. J., 35, 513 (2003).
20. K. Ito, K. Tanaka, H. Tanaka, G. Imai, S. Kawaguchi, and S. Itsuno, Macromolecules, 24, 2348 (1991).

21. S. Kawaguchi, G. Imai, J. Suzuki, A. Miyahara, T. Kitano, and K. Ito, Polymer, 12, 2885 (1997).

22. S. Kawaguchi, M. A. Winnik, and K. Ito, Macromolecules, 29, 4465 (1996).

23. R. Shen, C. Akiyama, T. Senyo, and K. Ito, to be published.

24. G. Baskar, K. Landfester, and M. Antonietti, Macromolecules, 33, 9228 (2000).

25. J. Ugelstadt, M. S. El-Aasser, and J. W. Vanderhoff, J. Polym. Sci., Polym. Lett. Ed., 17, 3069 (1979).

26. A. J. Paine, Macromolecules, 23, 3109 (1990). 